
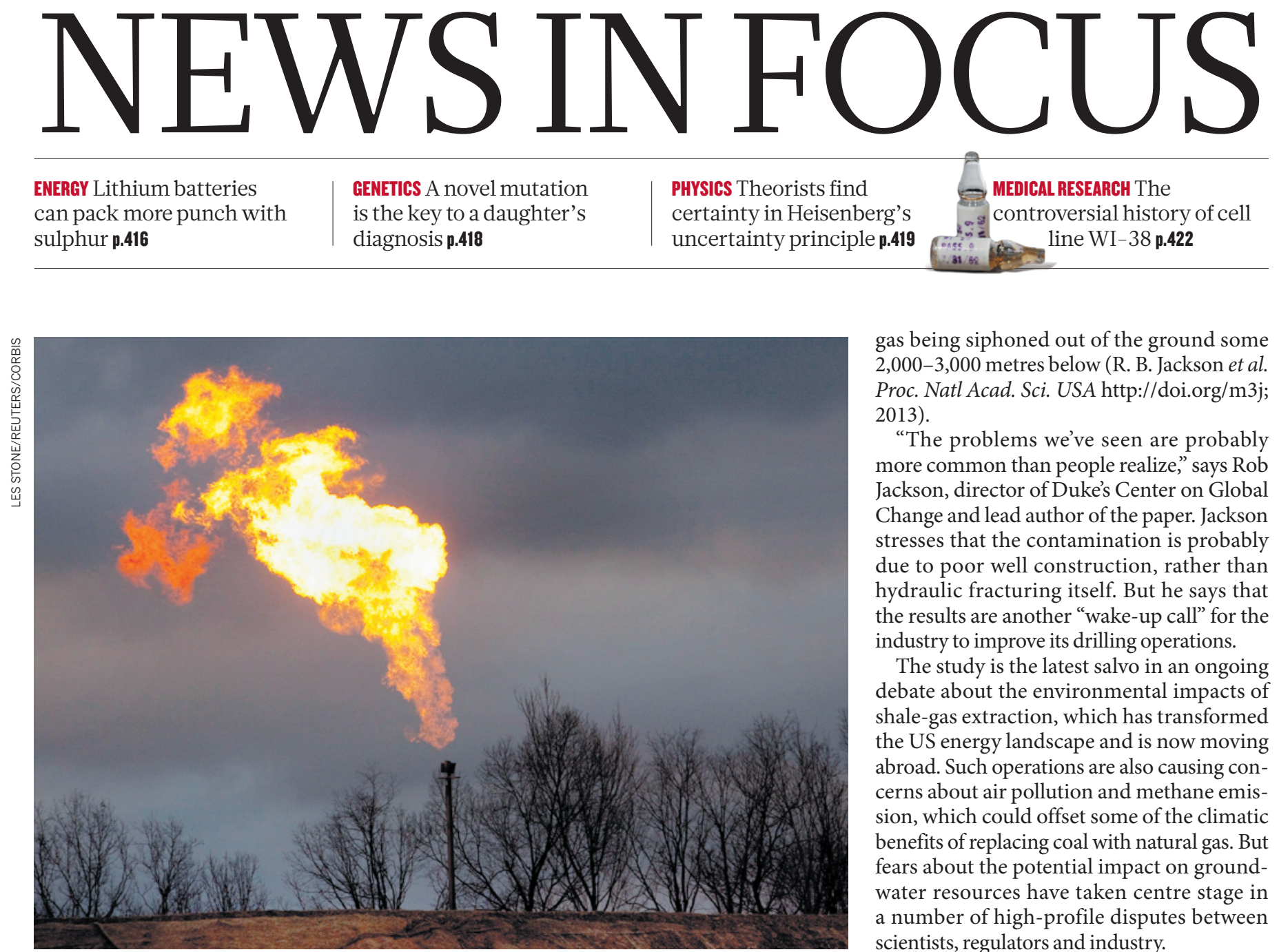

Shale-gas extraction has transformed the US energy landscape, but its environmental effects are unclear.

\title{
ENERGY
}

\section{Gas drilling taints groundwater}

\section{Chemical analysis links methane in drinking wells to shale-gas extraction.}

\section{BY JEFF TOLLEFSON}

A s shale-gas operations expand across the United States, industry officials and environmentalists are at loggerheads over whether or not shale-gas extraction can contaminate groundwater. Now researchers have traced low levels of methane and other contaminants to a source of shale gas: the sprawling Marcellus Formation, which lies beneath much of New York state, Pennsylvania, West Virginia and Ohio (see 'On tap') .

The study, led by researchers at Duke
University in Durham, North Carolina, expands on an earlier analysis of drinking water in northeastern Pennsylvania, where energy companies have used hydraulic fracturing (fracking) to crack the Marcellus Formation and release gas. In that work, the researchers found that contamination rates increased with proximity to wells (S. G. Osborn et al. Proc. Natl Acad. Sci. USA 108, 8172-8176; 2011). Their latest analysis, published on 24 June, goes a step further, by tying the chemical fingerprint of the groundwater contaminants to the gas being siphoned out of the ground some 2,000-3,000 metres below (R. B. Jackson et al. Proc. Natl Acad. Sci. USA http://doi.org/m3j; 2013).

"The problems we've seen are probably more common than people realize," says Rob Jackson, director of Duke's Center on Global Change and lead author of the paper. Jackson stresses that the contamination is probably due to poor well construction, rather than hydraulic fracturing itself. But he says that the results are another "wake-up call" for the industry to improve its drilling operations.

The study is the latest salvo in an ongoing debate about the environmental impacts of shale-gas extraction, which has transformed the US energy landscape and is now moving abroad. Such operations are also causing concerns about air pollution and methane emission, which could offset some of the climatic benefits of replacing coal with natural gas. But fears about the potential impact on groundwater resources have taken centre stage in a number of high-profile disputes between scientists, regulators and industry.

Last week, for example, the US Environmental Protection Agency (EPA) cancelled its probe of groundwater contamination in Pavillion, Wyoming, more than two years after issuing a controversial draft report pinpointing fracking as the cause. The decision leaves the investigation in the hands of state officials, who had criticized the EPA's assessment. And in Dimock, Pennsylvania, which lies in the area covered by the Duke research, allegations of groundwater contamination led state regulators to halt some drilling operations temporarily in 2009 and to fine the primary operator, Cabot Oil and Gas Corporation of Houston, Texas, which settled a lawsuit out of court but did not admit fault.

The Duke team's data provide further evidence that shale development could harm groundwater quality in some areas. Trace amounts of methane are often found in drinking water, and the levels identified by Jackson's team do not necessarily represent a health threat. But in extreme cases, methane contamination can be dangerous: homeowners can sometimes ignite the gas in water coming out of their taps.

Jackson's team found methane in 115 of the 141 shallow drinking-water wells that it sampled. To trace its source, the team examined carbon-isotope ratios of the methane molecules - these ratios differ depending 


\section{ON TAP}

The Marcellus shale contains about 2.4 trillion cubic metres of recoverable natural gas.

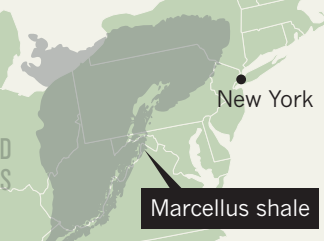

on whether the gas was produced by microorganisms in relatively shallow water or by heat and pressure deep in the Earth. The team also looked at the relative concentrations of ethane, propane and helium - other common by-products of gas extraction that are rare in shallow groundwater sources.

The results suggest that homeowners living up to 1 kilometre from shale-gas wells probably have groundwater contaminated by gas from the Marcellus Formation. But the team did not find evidence that chemicals used in fracking migrated from depth to contaminate aquifers. Jackson says that the methane is probably from leaks in the well casing itself, which would allow direct contamination. The data also suggest that some gas migrated up from geological layers between the Marcellus Formation and the groundwater table.

The data "raise important issues", says Mark Zoback, a geophysicist at Stanford University in California, who served on a high-level panel that in 2011 recommended improving industry practices to minimize environmental impacts. "There's a real need in the future to have this kind of sampling before, during and after shale-gas development."

Officials from Cabot, which operates most of the wells in this area, declined to comment on the study. Steve Everley, a spokesman for Energy In Depth, a research and advocacy arm of the Independent Petroleum Association of America, based in Washington DC, says the Duke study is inconclusive. He notes that recent baseline testing by the US Geological Survey found non-microbial methane in two groundwater wells in northeastern Pennsylvania even before drilling.

Jackson says that his results do not necessarily mean that all drilling operations will have problems. Other research by his team, now in the press in Applied Geochemistry, found no evidence of contamination in a shale formation in Arkansas. More importantly, he says, the results suggest that the problem is relatively simple to fix.

"This is about well integrity," he says. "The industry knows how to do this, and they work hard to maintain well integrity."

ELECTROCHEMISTRY

\section{Sulphur back in vogue for batteries}

\section{Lithium-sulphur batteries benefit from new materials.}

\section{BY RICHARD VAN NOORDEN}

A type of battery first proposed in the 1960 s is attracting a fresh surge of interest as scientists and engineers look for ways to extend the range of electric vehicles. The veteran system is the lithium-sulphur battery, now back in fashion as the limitations of expensive, low-capacity lithium-ion batteries become ever more apparent. Over the past two years, what was a trickle of publications has gathered into a wave (see 'The lithiumsulphur charge') as scientists wear down oncemajor stumbling blocks, and the area attracts more funding.

Chemists say that there is substance to the buzz. Although researchers are wary of overstating the case, "we believe that lithiumsulphur is the way to go", says Ilias Belharouak, a materials scientist who works on batteries at Argonne National Laboratory in Illinois. "There's promise from many different labs and some approaches really are working," adds Linda Nazar, a chemist who studies lithiumsulphur batteries at the University of Waterloo in Ontario, Canada.

Lithium-ion batteries, as their name suggests, shuttle lithium ions from one electrode to another, while forcing electrons around an outside circuit. Improving the energy-density of that system means finding a material that can hold more lithium. Decades ago, sulphur was tipped as a promising candidate ${ }^{1}$. It is cheap, abundant and can bond to large numbers of lithium ions. In theory, a battery with a metal lithium anode and a sulphur-based

\section{THE LITHIUM-SULPHUR CHARGE}

The number of research papers on lithiumsulphur batteries is rising fast.

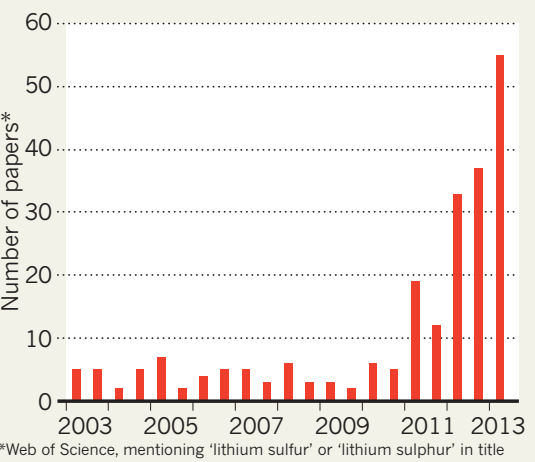

cathode can hold as much as five times the energy density of today's batteries, in which lithium ions are held (but not chemically bonded) within the pores of both the carbon and the metal-oxide-based electrodes (see 'How batteries stack up'). That translates into a greater range for vehicles.

So far, no one has managed to commercialize a lithium-sulphur battery that works well for more than a few dozen charging cycles. The problems are numerous: sulphur does not conduct ions well, so it is hard to get the lithium to move through the sulphur to exploit the whole cathode. And when the lithium ions do start bonding to sulphur atoms, they form soluble compounds - polysulphides - that dissolve in the electrolyte (the liquid through which the ions shuttle). As a result, the sulphur electrode gradually crumbles and the battery loses capacity as it is recharged. Moreover, the lithium metal electrode itself is reactive, although some companies, such as PolyPlus in Berkeley, California, have invented materials to protect it.

Some of these obstacles are now giving way. In 2009, Nazar's lab showed how to connect the lithium and sulphur atoms more closely by holding the sulphur within a dense network of carbon fibres a few nanometres apart ${ }^{2}$. Coating those same structures with water-loving polymers helped to trap the polysulphide products. Since then, hundreds of papers have reported related ways of structuring the electrode to function more efficiently.

In January, Yi Cui of Stanford University in California, and his team reported that sulphur nuggets held in titanium dioxide shells - like yolks protected in porous eggshells - maintained $70 \%$ storage capacity after 1,000 charging cycles ${ }^{3}$. And earlier this month, Chengdu Liang's group at the Oak Ridge National Laboratory in Tennessee, reported a new sulphurbased solid that conducts lithium ions ${ }^{4}$. A liquid electrolyte is no longer needed, Liang says, preventing the problem of soluble polysulphides altogether, and perhaps creating a safer system.

Jay Akhave, who works for the battery firm Altairnano in Reno, Nevada, says that Liang's find is a "key breakthrough", although other researchers disagree. Steven Visco, chief executive of PolyPlus, argues that Liang's new compound - in which long sulphur chains hang off a phosphorus-sulphur molecule - will not survive hundreds of charging cycles. 